\title{
Pharmacogenomics and personalized medicine: mapping of future value creation
}

Sean Xinghua Hu, Thomas Foster, and Ann Kieffaber

IMS Health, Fairfield, CT, USA

BioTechniques Vol. 39, N 0.4 (2005)

doi 10.2144/000112048

\section{PERSONALIZED MEDICINE}

People have been talking about personalized medicine, to a point that it almost gets old. Some are firm believers in this revolution and are actively devoting effort to advance it, others wonder whether this is yet another hype, and yet many others may have an impression that, as promising a future as it paints, it may only become reality in another lifetime. Regardless, most people seem to agree that personalized medicine is the trend of future. Correspondingly, just like any other major social/technological transformations in the world, it would bring along great value creation and reallocation among various stakeholders in the healthcare industry. Given its fundamental impact and implications on all different businesses related to healthcare, it is critical for senior management in the healthcare-related industries to have (or at least start to consider) a clear understanding of where the future value will lie, when it is coming, and how to best prepare the organization to capture the most value in this revolution.

Personalized medicine addresses current unfilled needs in the healthcare world by calling for the right treatment for the right individual at the right time. In current drug therapeutics world, it is widely observed that a drug doesn't work for all the patients all of the time. Drugs do not have the desired outcome in $30 \%-40 \%$ of

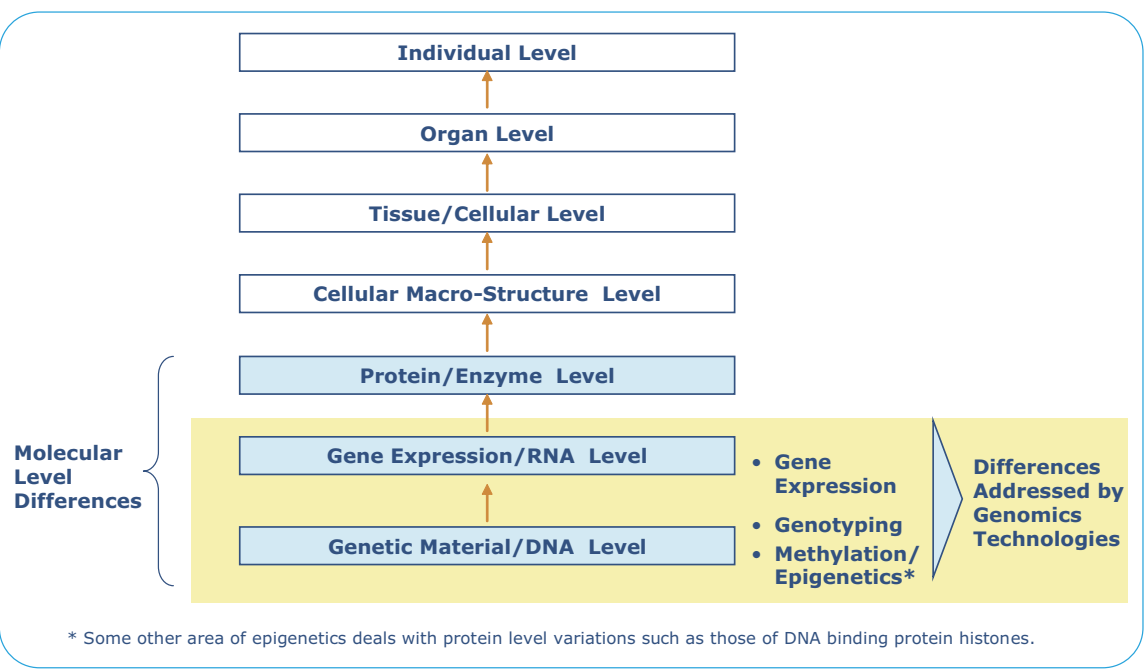

Figure 1. Various level of differences among individuals.

\begin{tabular}{|c|c|c|c|c|c|}
\hline Patient & $\begin{array}{l}\text { Self-Directed } \\
\text { Healthcare } \\
\text { Activities }\end{array}$ & $\begin{array}{c}\text { Triggers to } \\
\text { Advance to } \\
\text { Physician } \\
\text { Contact }\end{array}$ & $\begin{array}{l}\text { Physician } \\
\text { Interactions }\end{array}$ & $\begin{array}{c}\text { Diagnosis/ } \\
\text { Prognosis }\end{array}$ & Treatment \\
\hline & $\begin{array}{l}\text { - Investment of \$ } \\
\text { and effort in diet, } \\
\text { exercises, etc. } \\
\text { - Self-monitoring }\end{array}$ & $\begin{array}{l}\text { - Symptoms } \\
\text { - Periodic checkups } \\
\text { - Self-diagnosis } \\
\text { - Other }\end{array}$ & $\begin{array}{l}\text { - Office visit } \\
\text { - Hospital visit } \\
\text { - Visit other } \\
\text { healthcare } \\
\text { provider facilities }\end{array}$ & $\begin{array}{l}\text { - At point of care } \\
\text { - By central labs } \\
\text { - At imaging } \\
\text { facilities } \\
\text { - At other facilities }\end{array}$ & $\begin{array}{l}\text { - Medicine } \\
\text { - Surgery } \\
\text { - Physical therapy } \\
\text { - Other treatments }\end{array}$ \\
\hline
\end{tabular}

Figure 2. Current healthcare value chain.

October 2005 patients, blockbuster drugs are often efficacious in $40 \%-60 \%$ of the patients, and it is not unusual to see chemotherapy working for only $30 \%$ of cancer patients (from industry expert interviews, the American Medical Association; www.ama-assn.org/ama/pub/ category/7459.html). In addition, drugs can at times cause adverse drug reactions (ADRs), with some more severe than others.

There are different levels of variation among individuals (Figure 1) that could account for the varying outcomes of drug therapy, such as patients' different drug absorption, distribution, metabolism, and excretion (ADME) profiles measurable at organ, tissue, or cellular levels and more fundamental differences at molecular levels, [i.e., analyses of protein, RNA (gene expression analysis), and DNA (genotyping)]. Genotyping and gene expression analysis are current key component technologies of pharmacogenomics (PGx) that currently serves as the major driving force for the personalized medicine revolution.

\section{CURRENT HEALTHCARE VALUE CHAIN AND VALUE DISTRIBUTION}

To understand the future impact of personalized medicine, we can start by looking at the healthcare value chain. As shown in Figure 2, patients are typically the beginning point of the current healthcare value chain. The triggers for seeking healthcare are often disease symptoms or asymptomatic conditions uncovered during periodic checkups. Other than some self-directed diagnostic tests, most diagnostic activities are the consequence of either patients experiencing symptoms or of regular medical checkups. Treatment can be prescribed if needed.

Next, look at the current value distribution in the healthcare-related industries. Healthcare providers are obviously the most integral part of the chain, as they actually deliver the care, interacting with patients and providing or prescribing diagnosis and treatment. Currently, most pharmaceutical companies align themselves with the treatment part of the value chain by supplying therapeutics.

Diagnostics product manufacturers supply products that enable healthcare professionals, diagnosis service providers (such as central labs), or even patients to make various diagnoses. Medical device companies supply products as part of the diagnosis and treatment solutions. Among the plethora of companies that provide supporting, yet important, healthcare-related products and services, IMS Health (Fairfield, CT, USA) aligns itself with the pharmaceutical and biotech 


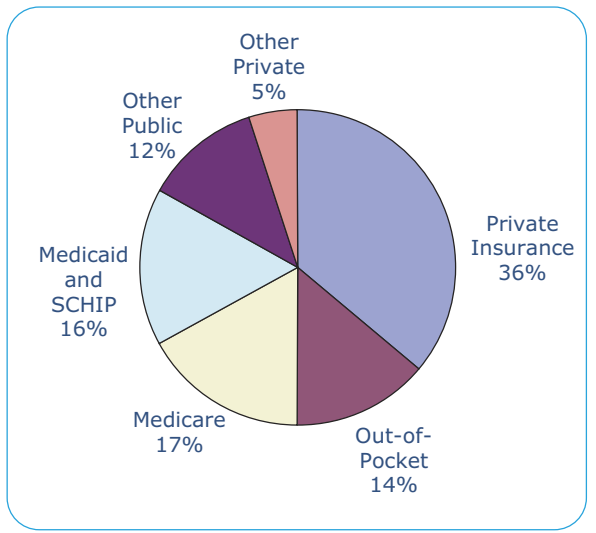

Figure 3. Allocation of U.S. healthcare expenditures (2003).

industries to provide market research information for their marketing, sales, and R\&D functions, as well as strategic solutions. Emerging $\mathrm{PGx} /$ genomics companies are on the rise. They are a fundamental driving force in this revolution, providing tools that enable the development of novel molecular-level diagnosis and treatment products that account for individual (or population segment) differences.

Reflecting the quantitative perspective of the activities within the above value chain, in the U.S., the national healthcare expenditures amounted to $\$ 1.7$ trillion in 2003 (U.S. Center for Medicare and Medicaid Services; www.cms.hhs.gov) as shown in Figure 3 . In 2003, the approximate value allocation to the U.S. pharmaceutical industry was about $\$ 219$ billion or $13 \%$ of the entire U.S healthcare expenditure. In 2004, the U.S. pharmaceutical market grew to $\$ 236$ billion, accounting for approximately $43 \%$ of the world market (IMS Health proprietary data). The diagnostics industry has a smaller share than the pharma industry, having captured about \$22-\$23 billion in $2003(1,2)$. The market for market research/sales information on the pharmaceutical industry, as represented by IMS Health's line of business, is roughly $\$ 2$ billion. The genomics industry (including PGx) is expected to experience double-digit growth in a few years and currently has a combined gene expression and genotyping market size of over $\$ 1$ billion.

\section{FUTURE HEALTHCARE VALUE CHAIN, NEW VALUE CREATION, AND ALLOCATION}

In the ideal future world of personalized medicine, the healthcare value chain would look quite different than it does today, as shown in Figure 4. The fundamental, scientific advancement underpinning this revolution in personalized medicine is our much-enhanced ability to understand human biology at the molecular level. For example, PGx focuses on which differences at the molecular level result in patients' having different responses to a drug treatment and

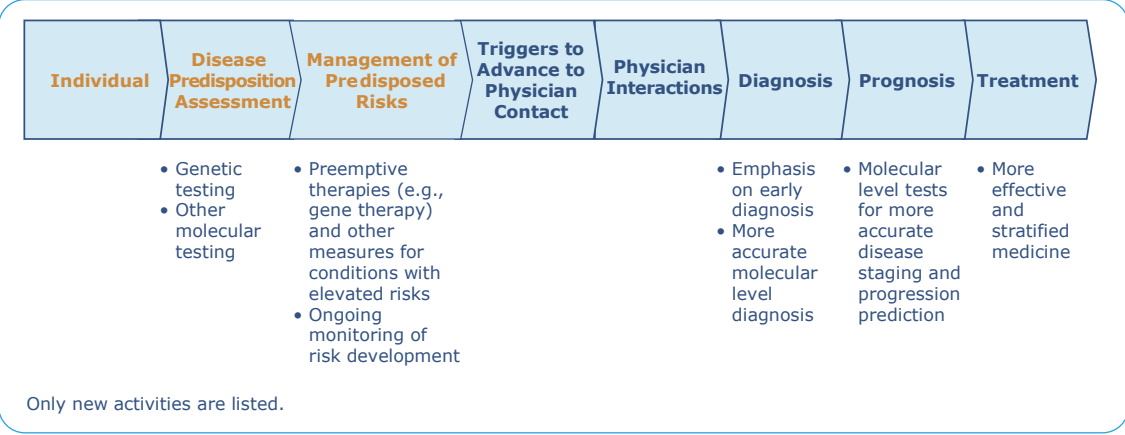

Figure 4. Future healthcare value chain. how to determine or develop drug treatments best suited to patients with particular molecular profile or types. Future disease diagnosis and prognosis protocols will allow us to diagnose a disease condition more precisely based on molecular-level indicators and more reliably prognosticate a condition in order to devise an optimal treatment regimen.

One of the most notable differences is that in the future, healthcare activities will start with "individuals" instead of with "patients" as they do in most cases today. This will mean that the healthcare value chain activities having the greatest social impact will most likely be disease predisposition assessment and management. Through those activities, healthy individuals could predict their genetic predisposition to develop certain diseases in the future-and, hopefully, manage their risks accordingly.

It follows that this new chain of events will bring about a New Value Creation, defined as a measure of benefit to patients and society, in a way very similar to that used in pharmacoeconomics assessment:

New Value Creation $=($ Avoidance of loss or potential loss of productivity due to disease or health-threatening conditions)

+ (Improvement of patients' quality of life)

We predict that future New Value Creation will mostly come from the following four areas: (i) molecular diagnosis and prognosis; (ii) stratified medicine or patient stratification to screen for responders and to screen out nonresponders or responders with undesired ADR; (iii) new and better medicine with higher efficacy and less ADR; and (iv) preemptive healthcare with disease predisposition assessment and management.

\section{Molecular Diagnosis and Prognosis}

We expect to see products from this area delivering benefits to patients sooner than in most other areas. Scientific advances will lead first to products that offer more accurate and earlier diagnosis as well as more reliable prognosis. The benefits to patients and payers are evident, given that many diseases, most notably cancer, would be more curable if diagnosed earlier, resulting in greater benefits to patients and lower healthcare costs. Consequently, when patients are cured better and sooner, New Value Creation will come from a reduction in lost productivity and an improvement in quality of life.

Additionally, molecular diagnosis and prognosis will serve as the basis of other areas of New Value Creation such as stratified medicine and preemptive healthcare. The New Value Creation from this area will be captured mostly by: (i) companies providing general genomics/PGx tools to enable the search for molecular diagnosis and prognosis indicators; (ii) companies discovering, developing, and commercializing molecular diagnosis and prognosis products; and (iii) organizations providing diagnostics and prognosis services.

\section{Stratified Medicine}

Stratified medicine is the stratification of patients to screen for super responders, nonresponders, or negative responders. This application of PGx has been a major area of discussion, but has received mixed views. Potentially, patients could be stratified into four segments: (i) responders or patients who do respond (positively) to a drug; (ii) super responders or subsegment(s) responding to a drug particularly wellbetter than and statistically distinguishable from the rest of the responders group (this segment may or may not exist depending 
on the particular drug); (iii) nonresponders or patients who do not respond to a drug (with respect to efficacy or ADR); and (iv) negative responders or patients who develop unacceptable ADRs in response to a drug.

There are obvious benefits to patients should stratified medicine become reality. As mentioned earlier, on average $30 \%-40 \%$ of patients do not respond to a given drug, and a relatively small percentage of patients have unacceptable (or even life-threatening in the worst cases) ADRs. Treating nonresponder patients with a nonresponding drug causes a delay in curing them and actually worsens their condition in some cases. According to a study of hospitalized patients published a few years ago, ADR is one of the leading causes of hospitalization and death in the U.S. [National Center for Biotechnology Information (NCBI); www.ncbi.nlm.nih. gov/About/primer/pharm.html]. In 1994, adverse drug reactions accounted for more than 2.2 million serious cases and over 100,000 deaths (NCBl; www.ncbi.nlm.nih.gov/About/primer/pharm.html), costing society about $\$ 100$ billion a year $(3,4)$. Thus, identifying nonresponders and negative responders could bring great benefits by avoiding delays in proper disease treatment, worsened conditions, or unacceptable ADRs, in addition to realizing cost savings through avoiding the non-optimal drug. On the other hand, super responders, if identified, could benefit more from the drug in question than alternative treatments. All of these benefits to patients lead to New Value Creation under the stratified medicine scenario.

We believe most of the New Value Creation will be allocated among diagnostic (or theranostic) products and among service companies that enable patient stratification, as well as among pharmaceutical companies, payers, and providers of information services related to patient molecular profiles (for information storage, protection, and utilization). While value allocation to diagnostics-related companies is straightforward, it is a far more complex situation for pharma companies.

Some of us may point out that patient stratification and segmentation leads to a smaller addressable market for a drug and is thus likely to reduce the total value that a pharma company could capture from it. Others may show a list of risks and challenges related to screening out negative responders, even if it could potentially save a drug from the fate of market withdrawal. These risks include: (i) Strategic risks. How much of a drug's life could be saved if it already has a tainted public perception? (ii) Potential legal liability risks. Can a diagnostic test guarantee to screen out $100 \%$ of the negative responders? Could there be lawsuits from negative responders who are not screened out? (iii) Scientific and statistical challenge. Due to the usually rather small percentage of negative responders, it is difficult and costly to collect enough patient samples to derive statistically significant results, especially with multifactorial conditions. In some other cases (e.g., gene expression analysis), disease tissue samples may be necessary for the assay, but difficult or even impractical to locate, biopsy, or preserve.

Knowing all those legitimate concerns, risks, and challenges, is there really any New Value Creation allocated to the pharma industry or to individual pharmaceutical companies? The analysis below will show that, even though for the pharma industry as a whole the total value to be captured might be limited, significant opportunity most likely exists for individual companies to extract great value, sometimes at the expense of their competitors.

Looking at the industry as a whole, the following are very simplified theoretical models. For the pharmaceutical industry, the total market value captured by all the drugs treating a disease (Total Captured Value) equals:

Total Captured Value $=[($ Size of patient population treated with drug 1) $\times$ (Average price of drug 1 for treating a patient)] $+[$ (Size of patient population treated with drug 2$) \times($ Average price of drug 2 for treating a patient)] + ...
In which,

(Size of patient population treated with a drug) $=$ (Size of total treated patient population) $\times$ (Market share of this drug)

in which market share refers to patient-based market share normalized by average pharmacoeconomic benefits of the drugs treating the disease. Theoretically, in an ideal world, a drug could not sell for a price higher than the pharmacoeconomic benefit that it could bring to the patients. Thus, Total Captured Value is capped at the total pharmacoeconomic benefits of the drugs (Maximum Captured Value) or:

Maximum Captured Value $=($ Size of total treated patient population) $\times$ (Average pharmacoeconomic benefits to a patient)

\section{Alternatively,}

Maximum Captured Value $=[($ Size of patient population treated with drug 1$) \times($ Average pharmacoeconomic benefits of drug 1 to a patient)] + [(Size of patient population treated with drug 2$) \times($ Average pharmacoeconomic benefits of drug 2 to a patient)] + ...

When nonresponders and negative responders are screened out, the size of total treated patient population will shrink, while the average pharmacoeconomic benefits to a patient will increase proportionally, allowing pharmaceutical companies to justify a higher price premium.

However the Maximum Captured Value will more or less remain the same, and it will be redistributed among the different healthcare industries. Among others, the diagnostics and theranostics product and service companies will take a slice of it, and the payers will likely demand to keep some benefits themselves. Accordingly, the net change of Total Captured Value for the pharma industry will likely be rather limited, if there is any gain at all, and in some cases could be negative (i.e., value could be lost).

At the individual pharmaceutical company level, however, the outcome could vary greatly. Essentially, as we evolve into an environment of stratified medicine, value will be redistributed among the competing pharma companies. Some will have opportunities to gain value at the expense of others.

Similar to the pharma industry analysis above, compare the value captured by a particular drug before patient stratification:

Maximum Captured Value $=($ Size of total treated patient population $) \times($ Current market share of this drug $) \times($ Current average pharmacoeconomic benefit of this drug to a patient)

\section{And after patient stratification:}

Maximum Captured Value $=$ (Size of treated patient population $) \times($ Future market share of this drug $) \times($ Future average pharmacoeconomic benefit of this drug to a patient)

A company's ability to gain value after patient stratification will be case-dependent. Post patient stratification, the future average pharmacoeconomic benefit of this drug to a patient will increase, allowing a drug manufacturer to seek higher drug prices. Meanwhile, a higher price premium may or may not be able to make up for the loss of patients categorized as nonresponders or negative responders. However, a company could have an additional-and possibly much greater-opportunity to gain. A company that could stratify patients for its drug, when its competitors could not, would have a marketing edge in a much-enhanced certainty of patients response, leading to a potentially increased market share from patients who would otherwise be treated with competing drugs.

In general, if super responders do exist and can be stratified, then the pharma industry as a whole would have a much better chance of capturing additional value. However, when there is only one drug in the market for treating a disease, all patients are 
prescribed with the same drug, regardless. There will be minimal to no incentive to identify super responders. When there are two or more competing drugs in the market, and especially when the super responders of one drug receive higher efficacy than from competing drugs, the Maximum Captured Value for the pharma industry can certainly increase in many cases as the result of rational matching of patients with optimal treatments.

To fully understand the complex dynamics, consider a hypothetical case. Before patient stratification (Table 1), we assume: (i) two drugs, $A$ and $B$, are the only two competing in the market from company $A$ and $B$, respectively; (ii) the size of total treated patient population is 100, and each patient takes the same amount of drug; (iii) both drugs have identical average pharmacoeconomic benefit to a patient at 1.3; and (iv) current market share of drug $A$ is $80 \%$ and drug $B$ is $20 \%$. The Maximum Captured Value by the pharma industry is 130 , with 104 allocated to company $A$ and the balance to company B.

\section{Table 1. Before Patient Stratification}

\begin{tabular}{|lll|}
\hline & Drug A & Drug B \\
\hline $\begin{array}{l}\text { Average pharmacoeconomic benefit to } \\
\text { a patient }\end{array}$ & 1.3 & 1.3 \\
$\begin{array}{l}\text { Market share } \\
\begin{array}{l}\text { Size of patient population treated with } \\
\text { a drug }\end{array}\end{array}$ & $80 \%$ & $20 \%$ \\
$\begin{array}{l}\text { Maximum captured value by individual } \\
\text { company }\end{array}$ & 104 & 20 \\
$\begin{array}{l}\text { Maximum captured value by the phar- } \\
\text { ma industry }\end{array}$ & 130 & \\
\hline
\end{tabular}

After patient stratification (Table 2), we assume that company $B$ finds that the patient population could be stratified into two segments: (i) $30 \%$ as super B responders with an average pharmacoeconomic benefit to a patient of 2 and (ii) $70 \%$ as B responders, with an average pharmacoeconomic benefit to a patient of 1 , which combined to give the mixed patient population an average pharmacoeconomic benefit to a patient of 1.3. In addition, drug $A$ is insensitive to drug B's stratification method (possibly because two drugs have different mechanisms of action). In a perfectly transparent and rational world, physicians would be willing to stratify the patients. For super $B$ responders, they would prescribe drug B. For B responders, physicians would have a choice to prescribe drug A or B. To simplify, assume they will all be prescribed with drug $A$, as on average those patients may still receive a benefit of 1.3 from drug $A$ instead of 1 from drug $B$. Now the Maximum Captured Value by the pharma industry becomes 151, with 91 allocated to company $A$ and 60 to $B$.

Table 2. After Patient Stratification

\begin{tabular}{|lll|}
\hline & Drug A & Drug B \\
\hline $\begin{array}{l}\text { Average pharmacoeco- } \\
\text { nomic benefit to a patient }\end{array}$ & 1.3 & 2 \\
$\begin{array}{l}\text { Market share } \\
\text { Size of patient population }\end{array}$ & $70 \%$ & $30 \%$ \\
treated with a drug & 70 & 30 (super B \\
$\begin{array}{l}\text { Maximum captured value } \\
\text { by individual company }\end{array}$ & 91 & 60 \\
$\begin{array}{l}\text { Maximum captured value } \\
\text { by the pharma industry }\end{array}$ & 151 & \\
\hline
\end{tabular}

There are two key findings from this case. First, the entire pharmaceutical industry has the potential to gain because the Maximum Captured Value increases from 130 to 151 as the result of maximizing drug benefits to patients by more rational patient-drug Pharmacogenomics matching. Second, company B could potentially gain great value from much increased Maximum Captured Value from 26 to 60 , partially at the expense of company $A$.

From the above analysis, it is evident that despite the overall benefit to patients, a particular pharmaceutical company could be at risk after patient stratification. On a case-by-case basis, it may result in a net gain or net loss for a particular drug company. Facing the potential risk of patient stratification, pharma companies have two choices: option 1, do nothing, or option 2, do something to proactively manage the risk and seek the right opportunities.

As has been observed, regulatory intervention is progressing, and social pressure is mounting. For this personalized medicine revolution, it is not a matter of whether or not it would happen, but of how quickly it will happen. What would be a better strategy, to act or to react?

There are some downsides for option 1 . The first downside is the possiblity of leaving money on the table for the company and the industry as a consequence of not being able to identify and capture opportunities that would result in net gains. The second downside is that, as the industry evolves, it may eventually be forced into a situation where it has lost the upper hand, such as company $A$ in the hypothetical case illustrated here.

To be successful with option 2, a company will want to identify opportunities with the best benefit-to-risk ratio in order to deploy the patient stratification approach to its own advantage. Later in this article, we will discuss potential strategies that a pharma company could employ to increase its odds of being successful when it chooses to be proactive. Despite the complexity of the situation, we also see some other potential business incentives for companies to choose option 2. As a way to manage drug development risks, patient stratification may result in better or faster trials. Less background noise could lead to fewer subjects being required in trials, with greater statistical significance in the trial data, which could in turn increase the odds of regulatory approval and better differentiation in the market.

In some cases, the stratified medicine approach may be the only way to get a drug to the market. On June 23, 2005, BiDi® (NitroMed, Lexington, MA, USA) was approved by the Food and Drug Administration (FDA) for heart failure in African-American patients. During clinical trials, BiDil failed to show statistically significant benefit for the general population. However, it was shown to be so effective among African Americans that the company stopped double-blind clinical trials and gave all patients the drug. We see this as one of the first winning cases of stratified medicine, and we certainly expect more down the road.

\section{New and Better Medicine}

Producing new drugs with higher efficacy and less ADR largely falls within the conventional territory of a pharma company's activities. Essentially, pharmaceutical companies can use the same PGx technologies to improve their R\&D productivities and develop new and better medicine. When it becomes reality, great New Value Creation will be evident, arising from new medicines that meet unmet needs and that have better efficacy and less ADR, resulting in more benefits to patients and reduced healthcare costs. New Value Creation will be mostly captured by the pharmaceutical industry, as well as biotech companies that supply the enabling technologies.

This area has been the topic of much of scientific discussion. Without going into great detail, we highlight below some of the means by which PGx/genomics technologies could deliver additional value by enhancing pharma R\&D productivity: (i) producing higher quality targets; (ii) providing early target screening and validation approaches; (iii) enabling faster lead validation and preclinical studies; (iv) filtering out non-optimal candidates early via toxicology screening; and (v) resulting in more efficient clinical development programs.

October 2005 


\section{Preemptive Healthcare}

We think the term preemptive healthcare, meaning the ability to assess and manage an individual's predisposition to a disease, would better reflect the value of personalized medicine revolution than predictive healthcare. Having the ability to foresee or estimate the probability of contracting a disease in the future is only a small part of future New Value Creation. The much greater impact will come from answering the "so what" question. In other words, if there is nothing one could do to actively manage the disease predisposition risk, many people would be rather reluctant or refuse to find out whether or not they have elevated risks for certain diseases. The greater value comes when science enables us to actively manage the disease predisposition risk, monitor it, and eventually preempt the disease condition. Pending future scientific breakthroughs, this will likely be a most significant area of New Value Creation, considering the size of the potential addressable population, the breadth of relevant disease areas, and the scope of future new business opportunities.

We foresee future New Value Creation in this area being allocated in these four business areas: (i) disease predisposition assessment including genetic analysis and other molecular analysis products and services; (ii) predisposed risk management including drug therapy products and other preemptive measures; (iii) ongoing predisposed risk monitoring including molecular diagnosis and other monitoring products and services; and (iv) individual molecular information management including storage, protection, and utilization.

There are mixed implications of all of this to the pharmaceutical industry. This new preemptive healthcare falls outside of the area of traditional pharmaceutical company activities. On the one hand, a successful preemptive healthcare outcome would cut patient flow down the healthcare value chain, representing a potential threat to value allocation to the traditional pharmaceutical industry areas. On the other hand, this new area will create tremendous unmet needs in predisposed disease condition management, opening up vast opportunities to the pharmaceutical industry for developing therapy-based disease predisposition management products. The net outcome will be a major value redistribution, shifting from downstream to upper-stream activities in the new healthcare value chain.

\section{PERSONALIZED MEDICINE: WHEN WILL IT HAPPEN?}

PGx and personalized medicine are rapidly evolving and developing. It is not difficult for senior executives of healthcarerelated industries to understand the potential value and paradigm change of this movement. However, the big questions are: how should a company get involved and, particularly, when? In this business, which is driven by scientific advancement, it takes time to develop a company's optimal position to capture the most future value. Getting involved only when everyone else can see what is coming would likely be too late to be seriously competitive, whereas investing too much too early could mean premature allocation of precious resources at the cost of other projects.

We are at the dawn of a new era. Our assessment is that we are likely already at an inflection point in history. Currently, the timing is right and critical for every company in the healthcarerelated industries to develop its own personalized medicine/PGx strategy. There are many ways to predict the progression curve of this movement. If one looks at some milestone events in this area (Table 3), one can clearly see the accelerated pace and sense the beginning of the personalized medicine era.
Table 3. Milestone Events in Personalized Medicine

\begin{tabular}{|c|c|}
\hline Year & Milestone Events \\
\hline 1990 & $\begin{array}{l}\text { The initiation of the Human Genome Project (HGP) } \\
\text { aiming at decoding the } 3 \text { billion genetic codes of the } \\
\text { human genome. }\end{array}$ \\
\hline 1998 & $\begin{array}{l}\text { Food and Drug Administration (FDA) approval of } \\
\text { Herceptin }{ }^{\circledR} \text { (trastuzumab)—arguably the first approved } \\
\text { pharmacogenomic drug, which targets the segment of } \\
\text { HER2-positive metastatic breast cancer patients and } \\
\text { is coupled with FDA-approved diagnostic tests- } \\
\text { a fluorescence in situ hybridization (FISH)-based } \\
\text { HER2 gene copy number test and/or an immuno- } \\
\text { chemistry-based HER2 protein expression level test. }\end{array}$ \\
\hline 2000 & $\begin{array}{l}\text { The first working draft of the human genome- } \\
\text { a key HGP milestone. }\end{array}$ \\
\hline 2002 & $\begin{array}{l}\text { Initiation of the International HapMap Project, aiming } \\
\text { to have an initial understanding of individual genetic } \\
\text { differences by mapping single nucleotide polymor- } \\
\text { phisms (SNP) haplotypes maps among four ethnic } \\
\text { groups: Caucasians, Han Chinese, Nigerians, and } \\
\text { Japanese. }\end{array}$ \\
\hline 2003 & $\begin{array}{l}\text { Official and successful completion of the HGP. } \\
\text { Launch of "one-whole-human-genome" on a single } \\
\text { microarray gene expression analysis product. }\end{array}$ \\
\hline 2004 & $\begin{array}{l}\text { Grant of CE mark (European Conformity) in Europe } \\
\text { (EU) to the first DNA microarray-based genetic testing } \\
\text { product. } \\
\text { Launch of the first standard whole genome genotyp- } \\
\text { ing product targeting 100,000 SNPs on a set of two } \\
\text { microarrays. } \\
\text { Launch of "six-whole-human-genomes" on a single } \\
\text { microarray gene expression analysis product. } \\
\text { FDA clearance of the first microarray system for in } \\
\text { vitro diagnostics use. }\end{array}$ \\
\hline & $\begin{array}{l}\text { FDA approval of the first DNA microarray- based } \\
\text { genetic testing product. }\end{array}$ \\
\hline
\end{tabular}

Completion of the International HapMap Project.

FDA publication of Guidance for Industry Pharmacogenomic Data Submissions.

Launch of the industry's first standard microarraybased genotyping product for the major histocompatibility complex (MHC) region-a highly polymorphic

2005 region mostly responsible for determining the histocompatibility for applications like transplantation donor matching, etc.

Launch of the industry's first 100,000 SNP whole genome genotyping product on a single microarray and primarily targeting gene encoding regions.

FDA approval of the first ethnic-specific drug for African Americans, BiDil, a medicine not shown to be statistically significant over placebo in trials with mixed patient populations, but highly efficacious among African Americans. 


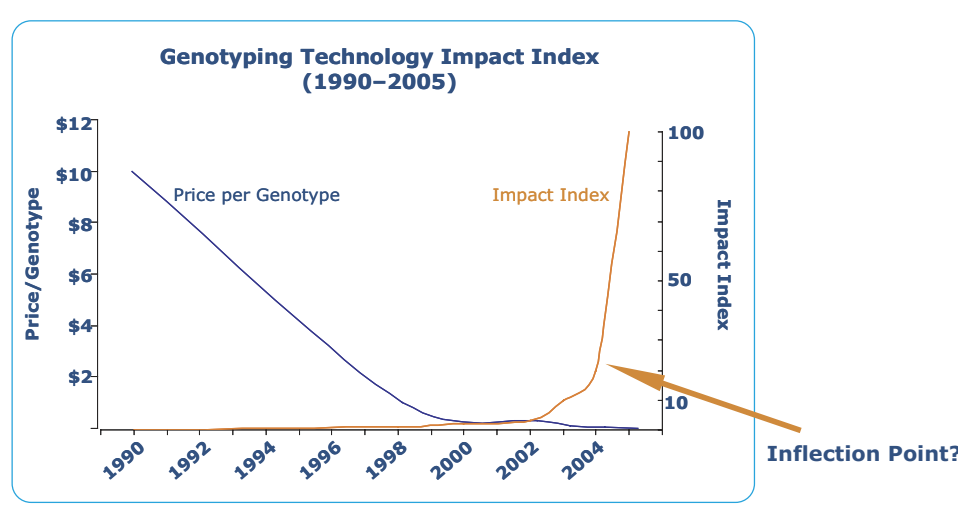

Figure 5. Impact Index of the SNP genotyping technology.

We would also like to introduce the concept of the Impact Index as another way to look to the future. We find it interesting and revealing to look at the relationship between the unit price of key products in a technology-driven business and its impact-defined as the extent of adoption, or popularity, of that technology. For example, in the PC industry -an analog to the highly technology-driven business of PGx and personalized medicine, the PC-unit price could be represented by price per $\mathrm{MHz}$ of CPU speed. Fifteen years ago, $\$ 1000$ could probably purchase an Intel $486 \mathrm{CPU}$-powered PC with a CPU speed of $16-33 \mathrm{MHz}$. Today, the same amount of money (in nominal terms-it would be even more telling if it were in real terms) could do much better: one could get a PC with a $3 \mathrm{GHz}$ CPU. Looking at its impact-the extent of adoption or popularity of a $\mathrm{PC}-$ consider that 15 years ago PCs were still mostly available at institution levels, where as today, they are used almost daily even by children $5-8$ years in age. One would arrive at similar conclusions if impact were defined as the total market size of the industry. Given the widely observed correlation between the unit price of a technology-driven product and its impact level, the Impact Index is simply defined as the inversion of unit price:

$$
\text { Impact Index }=1 / \text { Unit Price }
$$

Similar progresses are being made in the PGx industry, which in turn are driving personalized medicine. The unit prices for gene expression analysis and genotyping technologies have been decreasing drastically in the past one and one-half decades. Consequently, their Impact Indices have been going up. Take, for example, SNP genotyping, which is the most popular among all genotyping approaches, the progressive change of unit price, defined as the price/genotype or the cost to derive the information of one genetic code-a DNA base identified at a specific location (based on major genotyping product prices from industry intelligence, additionally the SNP genotyping unit price in 1990 was based on the then current per-base sequencing cost, as no other mature SNP genotyping technology was available at the time; see Reference 5), is illustrated in Figure 5. Back in 1990 at the beginning of the Human Genome Project (HGP), it cost about $\$ 10$ to obtain genotype information at a specific base using sequencing technologies. Today with the introduction of standard whole genome SNP genotyping products by such companies as Affymetrix (Santa Clara, CA, USA) and Illumina (San Diego, CA, USA), the per-genotype cost has gone down to as low as one cent.

The Impact Index curve shown in Figure 5 is an impressive exponentially shaped curve and is very telling. After nearly one and one-half decades of incubation time since the beginning of this era (when humankind organized globally to understand the fundamental genetic elements of human beings), the impact of genomics/PGx has finally evolved into a phase of exponential growth, indicating that we are most likely already at an inflection point in history. It is about time, in our opinion, for the senior management of all healthcare-related companies to devise personalized medicine strategies, so as to position their companies to capture the most New Value Creation in this revolution.

\section{ACKNOWLEDGMENTS}

We would like to thank Lance Longwell and the IMS Public Relations Department for their valuable review and edits to the manuscript.

\section{COMPETING INTERESTS STATEMENT}

S.X.H. is part of the Product \& Portfolio Development Strategy group at IMS Management Consulting and is currently co-developing the Licensing/Business Development Practice. T.F. is currently VP, consulting, and the global practice leader, Product \& Portfolio Development Strategy group at IMS Management Consulting. A.K. is currently Sr. Vice President, Consulting and Services, IMS Health.

\section{REFERENCES}

1. RBC Capital Markets. 2003. Equity research report, The In-Vitro Diagnostics Industry, Dec. 5th, 2003.

2. Robert W. Baird \& Co. 2003. Equity research report on Beckman Coulter, Inc. Sept. 23rd, 2003.

3. Lagay, F. 2003. Pharmacogenomics: revolution in a bottle? American Medical Association; http://www.ama-assn.org/ama/pub/category/7459.html.

4. Ingelman-Sundberg, M. 2001. Pharmacogenetics: an opportunity for a safer and more efficient pharmacotherapy. J. Intern. Med. 250:186.

5. Lander, E., B. Austin, J. Peterson, and J. Schloss. 2002. Sequencing and re-sequencing the biome! National Human Genome Research Institute; www.genome.gov/10005564.

Address correspondence to:

Sean Xinghua Hu

IMS Management Consulting

660 West Germantown Pike

Plymouth Meeting, PA 19462, USA

e-mail: SHu@us.imshealth.com 